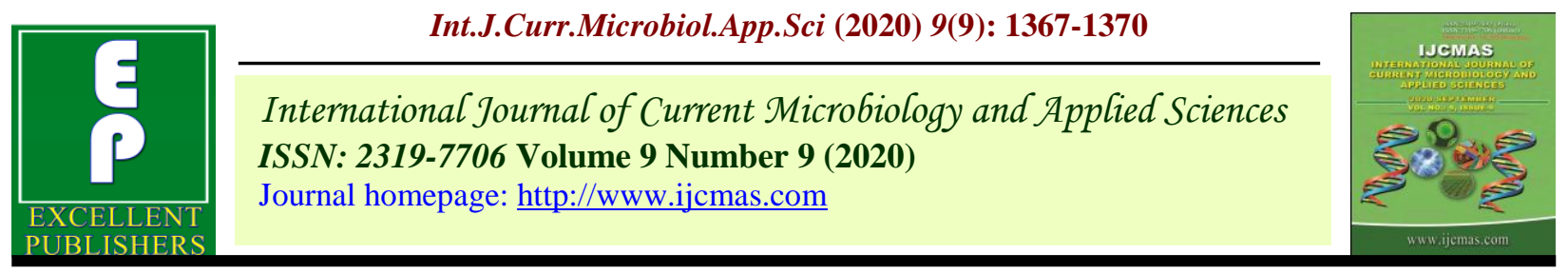

Case Study

https://doi.org/10.20546/ijcmas.2020.909.173

\title{
Management of Foetal Dystocia (Triplets) due to Breech Presentation in a Jamunapari Goat: A Case Report
}

\author{
A. Senthilkumar* and S. Murugesan \\ Farmers Training Centre, Tamil Nadu Veterinary and Animal Sciences University, \\ Theni- 625 531, India \\ *Corresponding author
}

\begin{abstract}
A B S T R A C T
Keywords

Breech

presentation-

Dystocia-

Jamunapari-

Management-

Treatment

Article Info

Accepted:

12 August 2020

Available Online:

10 September 2020

Dystocia or difficulty in parturition in a doe may need veterinary assistance for the successful parturition. An adult crossbred Jamunapari doe weighing $60 \mathrm{~kg}$ was presented to Farmers Training Centre, Theni with the history of difficulty in giving birth and animal straining continuously. Fetus tail was observed as protruding out from vulva. Through physical evaluation of the doe by per vaginal examination, the condition was diagnosed as fetal dystocia. Treatment and management plans given to the doe were manipulative delivery of the three live fetuses via repulsion and traction method. Post-operative treatment was given with Inj. ceftrifur sodium @ $0.1 \mathrm{mg} / \mathrm{kg}$ bwt I/v, Inj. Flunixin meglumine (dosed at $2.2 \mathrm{mg} / \mathrm{kg}$ bwt) and fuilds therapy once in a day for 5 days. The case was completely cured after 2 weeks.
\end{abstract}

\section{Introduction}

Dystocia refers to the condition in which animal fails or difficulty to expel the fetus at the time of parturition and human intervention becomes a necessity (Youngquist et al., 2007 and Blood et al., 2011). There are two types of factors that lead to incidence of dystocia in goats Firstly, the fetal factors which include oversized fetus, kid/lamb malpresentation, malposition, postural defects and congenital abnormalities. Secondly, the maternal factors which include over feeding of dam during pregnancy, uterine inertia in polytocous goats and small diameter of pelvic canal (Pugh et $a l ., 2012)$. The risk of losing the kid and its mother increases with delay in treatment of dystocia and prolonged dystocia in goats may cause necrotic metritis which is usually fatal (Mee, 2008; Christos et al., 2012). Dystocia cases can either be handled medically or surgically (Scott, 2006.). In goat, out of all cases of dystocia the reported incidence ranged from 20 to $30 \%$ (Jackson, 1995; Noakes et al., 2009). For goats, the incidence of dystocia is difficult to interpret as they are kept in smaller herds and at many locations as individuals. In one study, the incidence of 
dystocia in goats was $8.23 \%$ (Mehta et al., 2002). Obstetrical problems in goats are similar to those in sheep (Rahim and Arthur, 1982; Majeed, 1994), however, the incidence of dystocia is considered higher in goats compared to ewes (Sharma et al., 1999).The ability of the veterinary personnel to distinguish kidding difficulties is considered as an important step in treating dystocia. Majeed and Taha (1989) reported the incidence of dystocia in Goats were $52.9 \%$ fetal and $47.1 \%$ maternal dystocia. Fetal dystocia occurred due to anterior $(39.5 \%)$ or posterior presentation $(7.25 \%)$ of kids. Failure of the cervix to dilate was responsible for $27.4 \%$ cases. Dystocia occurred more in goats having male $(63.4 \%)$ than female kids (36.6\%). Mortality rate of the kids was $61.1 \%$. In this communication, a case of dystocia due to breech presentation in a Jamunapari goat is reported. In this communication, a case of dystocia (triplets) due to breech presentation in a crossbred Jamunapari goat is reported.

\section{Case history and observation}

Three years old crossbred Jamunapari goat in second parity completed full gestation period was presented at Farmers Training Centre Theni during noon hours for not delivering fetus since today morning 12.00 A.M. The water bag has ruptured and foetal tail was hanging from the vulva but goat was not delivering the kids for the past one hour. All the vital signs were normal and straining continuously. On external examination, tail was hanging from the vulva. Before the pervaginal examination, the external genitalia was cleaned with a weak potassium permanganate solution. Lubrication of sleeved hand is done with sweet oil and careful pervaginal examination was done. The cervix was dilated completely and presence of fetal reflexes indicated that the fetus was alive. The foetus was in posterior longitudinal presentation, dorso-sacral position with complete retention or extension of the rear limbs beneath the body. Thus the diagnosis was made that dystocia was due to breech presentation.

\section{Management of dystocia}

\section{Correction followed by repulsion and traction}

After proper lubrication of birth canal with liquid paraffin correction of the posture of fetus was performed using the repulsion and traction method where the fetus was pushed back into the uterine cavity to correct the posture by grasping the cranial aspect of tibia the foetal leg back into a hock-flexed posture as the fetal hind quarters were repelled forwarded and up warded and the live fetus was then pulled out manually by applying gentle traction on hindimbs. Further per vaginal examination revealed presence of two more live fetuses with same breech presentation which were assisted in delivery (Fig. 1). Placenta got expelled 30 minutes later. The doe did not exhibit secondary complications like uterine straining or prolapse after relieving dystocia.

\section{Treatment and Discussion}

The goat was treated with Inj. Ringer's lactate $250 \mathrm{ml} \mathrm{I} / \mathrm{v}$, Inj. Dextrose 25\% $250 \mathrm{ml} \mathrm{I} / \mathrm{v}$, Inj. Calcium Borogluconate @1ml/kg bwt I/v, Inj. ceftrifur sodium @ $0.1 \mathrm{mg} / \mathrm{kg}$ bwt I/v, Inj. Flunixin meglumine @ $2.2 \mathrm{mg} / \mathrm{kg}$ bwt I/m, Chlorpheneramine maleate @ $0.5 \mathrm{mg} / \mathrm{kg} \mathrm{bwt}$ $\mathrm{i} / \mathrm{m}$ and intrauterine dispensing of Furea (Pfizer India Ltd.) bolus $1 \mathrm{gm}$ was given to hasten the involution of uterus and control the infection. The owner was advised to continue the same treatment for 5 days. The animal was found to respond well to the treatments and the animal recovered successfully. 
Fig.1 Jamunapari Doe with triplets live kids after management of dystocia due to breech presentation
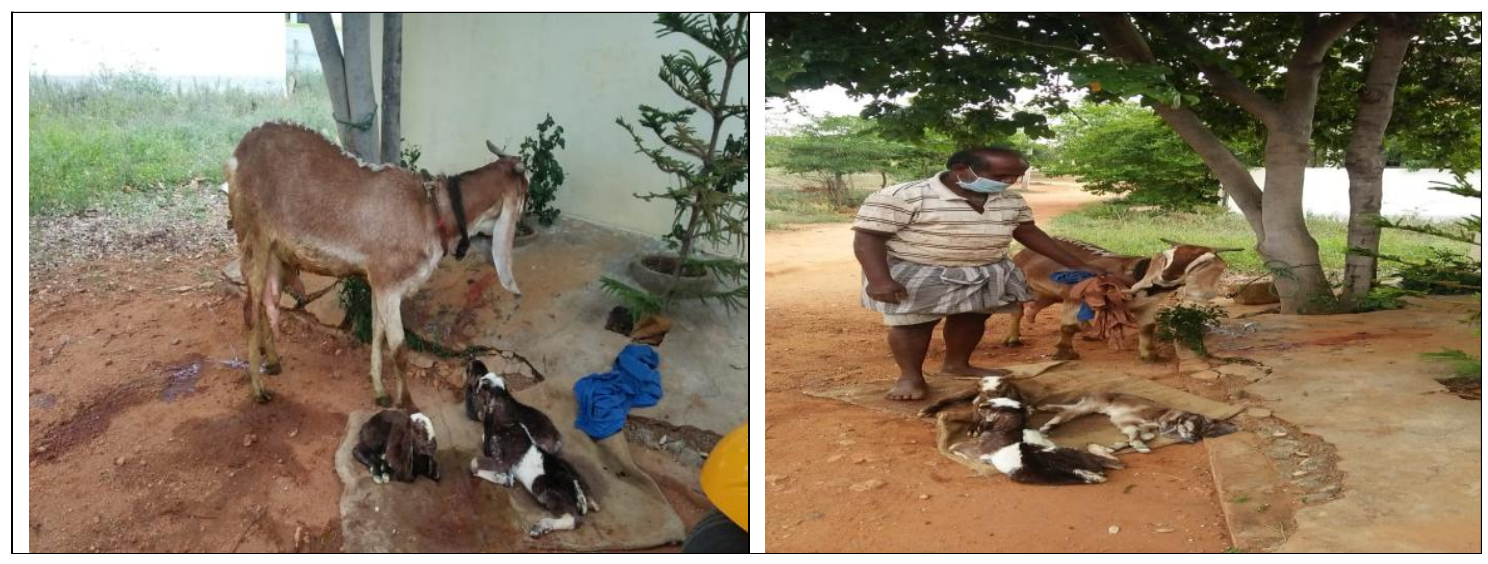

The management of dystocia are in agreeable with Ismail (2017) reported that manual extraction of fetus by per vaginal correction of dystocia due to mal disposition in small ruminants is of limited use. If the dam is presented with complete cervical dilatation and is carrying a fetus of normal size, per vaginal delivery can be attempted by repulsion, mutation, and traction. In cases where more than one fetus is presented to the birth canal then one of them should be removed first followed by the other.

Dystocia or difficult birth, a obstetrical problem in goat, results in high economic losses to goat farmers either due to death of kids or does or adversely affecting doe reproductive performance or fertility (Mcsporran, 1980). There are several factors affect the reproductive performance of the goat lead to decrease their numbers which result from the death of the kids and the does. One of the most important factors which lead to high economic losses was the dystocia (Abdul-Rahman et al., 1999). The causes of dystocia have been reported either due to maternal or fetal in origin (Arthur et al., 1996). Successful management and treatment of dystocia depends upon correct diagnosis of the causes of dystocia and when it started
(Aziz and Taha, 1996). These techniques of management including manual correction like mutation repulsin and traction, fetatomy, hormonal and caesarian section (Taha et al., 2005). In conclusion, by determining the factors rapidly, the occurrence of dystocia can be prevented or treated quickly to save the lives of the dam and the fetus as well as to prevent economic losses. Timely correction of such emergencies can prevent complications and can further improve the chances of survival. Management of obstetrical emergencies not only involves saving the life of dam and offspring but also conserving the future breeding soundness of the animal. Most of the dystocia with two or three fetuses / kids, one foetus was malpresentation, malposition, postural defects and others fetuses/ kids were normal. But in this present case report is unique case goat dystocia duo to all triplets kids were breech presentation.

\section{References}

Abdul-Rahman, L.Y., Al-Janab, I.A.S., Asofi, M.K., 1999. Causes of dystocia in Iraqi local goats reared in field stations. The Veterinarian 9(1):18-21.

Arthur, G.H., Noakes, D.E., Pearson, H., Parkinson, T.J., 1996. Veterinary 
Reproduction and Obstetrics. 7th ed. WB Saunders company limited.

Aziz, D.M., Taha, M.B.1996. Dystocia in Awassi ewes: causes and treatments a review. Iraqi Journal of Veterinary Science. 9(1):1-12.

Blood, D.C., Studdert, V.P and Gay, C.C.,2011. Saunders Comprehensive Veterinary Dictionary (4th Edition). London: Saunders.

Christos, N.B., Lazaridis, L., Karagiannis, I., Kiossis, E., Tsousis, G., Psychas, V and Nektarios, D.G.,2012. Prolonged dystocia, uterine necrosis, and ovariohysterectomy in a Chios ewe. Turkish Journal of Veterinary and Animal Sciences, 36

Ismail, Z. B., 2017. Dystocia in sheep and goats: Outcome and fertility following surgical and non-surgical management. Mac. Vet. Rev. 40(1): 91-96.

Jackson, P.G.G., 1995. Handbook of Veterinary Obstetrics. W.B. Saunders Co. Ltd., UK.

Majeed, A.F. 1994. Obstetrical problems and their management in Iraqi goats. Small Ruminant Research 14: 73- 78.

Majeed, A.F and Taha, M.B.,1989. Dystocia in local goats in Iraq. Small Ruminant Research1989,2(4):375-381.

Mcsporran, K.D., 1980. Dystocia in Sheep. In: Current Therapy in Theriogenology. Morrow, D.A., (2nd edn.). W.B. Saunders Co., Philadelphia.

Mehta, V., Nagar, D., Yadav, R.C., Garg, N. and Purohit, G.N. 2002. Obstetrics problems in goats. Vth National Seminar on Indian Society for Sheep and goat Production and utilization, December 30-31, Jaipur, pp. 151.

Mee, J.F., 2008. Prevalence and risk factors for dystocia in dairy cattle: A review. The Veterinary Journal, 176: 93-101.

Noakes, D.E., Parkinson, T.J., England, G.C.W., 2009. Noakes's' veterinary reproduction and obstetrics. London, Saunders

Pugh, D.G and Baird, N.N.,2012. Sheep and goat medicine. Elsevier Health Sciences).

Rahim, A.T. and Arthur, G.H. 1982. Obstetrical conditions in goats. Cornell Veterinarian 72: 279- 284

Scott, P.R.,2006. Sheep medicine. Manson Publishing

Sharma, V.K., Suthar, B.N., Parsani, H.R and Ojha, S.C. 1999. A clinical study on dystocia in small ruminants. XVth Annual Convention and National Symposium on Biotechniques in Optimizing Fertility in Farm Animals. PAU, Ludhiana, Abstracts, op. 94

Taha, M.B., Bashee,r E.B., Al-Kass, Z.M.,2005. Clinical study of dystocia in Awassi ewes (causes and treatments). Iraqi Journal of Veterinary Science. 19(1):55-61.

Youngquist, R.S and Threlfall, W.R.,2007. Current therapy in large animal theriogenology (2nd Edition). Elsevier Health Sciences.

\section{How to cite this article:}

Senthilkumar, A., and Murugesan, S. 2020. Management of Foetal Dystocia (Triplets) due to Breech Presentation in a Jamunapari Goat: A Case Report. Int.J.Curr.Microbiol.App.Sci. 9(09): 1367-1370. doi: https://doi.org/10.20546/ijcmas.2020.909.173 